\title{
BMJ Open Retrospective review of work-related injuries sustained by foreign workers: a single centre experience over 10 years
}

\author{
Yong Jing Daniel Quek (D) , ${ }^{1}$ Shilpa Vijayasrinivasan, ${ }^{2}$ Aishwarya Narayanan, ${ }^{2}$ \\ Kum Ying Tham ${ }^{1}$
}

To cite: Quek YJD,

Vijayasrinivasan S, Narayanan A, et al. Retrospective review of work-related injuries sustained by foreign workers: a single centre experience over 10 years. BMJ Open 2021;11:e042427. doi:10.1136/ bmjopen-2020-042427

- Prepublication history for this paper is available online. To view these files, please visit the journal online (http://dx.doi. org/10.1136/bmjopen-2020042427).

Received 06 July 2020 Revised 11 April 2021 Accepted 20 April 2021

Check for updates

(C) Author(s) (or their employer(s)) 2021. Re-use permitted under CC BY-NC. No commercial re-use. See rights and permissions. Published by BMJ.

${ }^{1}$ Emergency Department, Tan Tock Seng Hospital, Singapore ${ }^{2}$ Tan Tock Seng Emergency Department, Ministry of Health Holdings Pte Ltd, Singapore

Correspondence to Dr Yong Jing Daniel Quek; daniel_yj_quek@ttsh.com.sg

\section{ABSTRACT}

Objectives To investigate current patterns of work-related injuries sustained by foreign workers in Singapore and compare them to a decade ago. Secondary aim to analyse usefulness of selected trauma scores in this context. Design Retrospective review of trauma registry of a single centre, from 1 April to 30 June 2015. Data compared with those from similar study performed at same centre in 2004.

Setting Emergency department (ED) of 1500-bedded acute urban public hospital in Singapore.

Participants 1094 foreign workers with work-related injuries were included. Tourists, foreign students, nonwork-related injuries, re-attendances for the same condition were excluded.

Results Mean age of participants was 32.8 years (SD 7.8), 90.0\% were men. ED attendance was lowest on Sundays. Mechanism of injury: blunt (78.2\%), penetrating (19.2\%), burns (2.6\%). Compared to $2004,5 \%$ of foreign workers required admission (vs $19.6 \%$ in 2004, $\mathrm{p} \leq 0.0001$ ), $8.0 \%$ underwent day or inpatient surgical procedures (vs $13.2 \%$ in 2004, $p \leq 0.0001$ ), $41.6 \%$ were referred to specialist outpatient clinics (vs $27.6 \%$ in 2004, $p \leq 0.0001$ ), $12.5 \%$ were referred to primary care follow-up (vs $29.9 \%$ in 2004, $p \leq 0.0001$ ). Mean duration of sick days was 4.3 (vs 5.1 in 2004, p $\leq 0.0001$ ). Of admitted patients, $49.1 \%$ had extremity injuries and $36.3 \%$ had head and neck injuries. Mean Injury Severity Score (ISS) for admitted patients was 3.64 (SD 3.1) (vs 4.3 (SD 5.5) in 2004, $\mathrm{p}=0.39$ ). Mean Revised Trauma Score (RTS) for admitted patients was 7.74 (SD 0.39) (vs 7.8 (SD 0.2) in 2004, $\mathrm{p}=0.07)$. Of discharged patients, $48.9 \%$ had extremity injuries and $48.9 \%$ had external injuries. There was no death.

Conclusion Compared to 2004, there were fewer major/ fatal work-related injuries and an increased proportion of minor injuries. ISS and RTSs were of limited use in this setting.

\section{INTRODUCTION}

Singapore has a population of 5.63 million (June 2019). A substantial 1.43 million are foreign workers. Of these foreign workers, 999000 hold work permits. The majority of whom originate from Bangladesh, India and China and take up low-skilled work in selected sectors (construction, manufacturing,

\section{Strengths and limitations of this study}

A similar study done in the same centre 10 years ago allows for comparison.

- Information extracted from a well-maintained trauma registry helped reduce missing data.

- Inherent limitations of single centre study design.

- Lack of data on nature of occupation may limit generalisability of findings to all foreign workers.

- Information on types of industries served by the catchment area of the hospital not collected.

marine, shipyard, process or service). ${ }^{1}$ The leading cause of hospitalisation in Singapore is accident, poisoning and violence, making up $8.4 \%$ of total discharges from hospitals. ${ }^{2}$ A 1999 study conducted by Chen et al found that $43.4 \%$ of foreign workers who visited the emergency department (ED) came for injuryrelated conditions, the major cause of which was work-related injuries. ${ }^{3}$ The economic costs of work-related injuries and workers' ill health is staggering - they amounted to an estimated loss of $\mathrm{S} \$ 10.45$ billion, or about $3.2 \%$ of the gross domestic product in Singapore in 2011.

The Singapore Workplace Safety and Health (WSH) report 2016 showed that while there has been a stagnation in workplace fatal injuries from 2015 to 2016, there has been an overall decreasing rate since 2004 . The workplace fatality rate in 2004 was 4.9 per 100000 compared with 1.9 per 100000 in 2015. ${ }^{5}$ Further, workplace injury rate has also improved, from 460 per 100000 employed persons in 2007 to 364 per 100000 employed persons in 2015. ${ }^{6}$ Some of this overall improvement in workplace fatality and injury rate may be attributed to the introduction of the Singapore WSH Act in March 2006. This replaced the 'Factories Act' of 1973, which was found to be insufficient to enforce WSH legislations during a time of mounting workplace injuries and fatalities. ${ }^{7}$ The WSH 
Act moved away from a more prescriptive stance and introduced a performance-based regime focusing on systems and outcomes rather than compliance. Another vital piece of legislation in the past decade is the "Work Injury Compensation Act' (WICA) introduced in 2008, replacing the 'Workmen's Compensation Act'. ${ }^{7}$ The act and its subsequent amendments (2012, 2019) spell out the responsibilities of employers in providing healthcare financing for foreign workers with the minimum coverage amount increasing over the years.

The Singapore WSH report defines major injuries as 'non-fatal' injuries which are more severe in nature using a combination of factors including nature of injury, body part injured, incident type and duration of medical leave. Minor injuries are defined as 'an injury, other than fatal injuries and major injuries, which results in more than 3 days of medical leave or at least 24 hours of hospitalisation'. Based on these definitions, major injuries in the workplace were reported to have decreased by only $0.5 \%$ from 2015 to 2016 , and increased again by $5.5 \%$ from 2018 to 2019. ${ }^{8}$ Comparatively, minor injuries were noted to have risen by $5.7 \%$ from 2015 to 2016 , and again increased by $7.7 \%$ from 2018 to $2019 .^{8}$

This study was conducted as a follow-up study to one conducted a decade ago (2004), to investigate the current patterns of work-related injuries sustained by foreign workers in Singapore. ${ }^{9}$ We also aim to analyse the usefulness of selected trauma scores in assessing the severity of such injuries.

\section{BACKGROUND}

The last published medical study on work-related injuries sustained by foreign workers in Singapore was in 2004 by Carangan et al. In that study, adult victims of work-related injury who presented to the same pubic hospital as in the current study, over a 6-month period, were interviewed. Chart reviews were done for those hospitalised. Data collected were those of demographic, nature of injury, ambulance care, ED and hospital care, outcome and final diagnoses. The study included 1244 local workers and 1936 foreign workers. Key findings of the paper include that compared with local workers, foreign workers were younger and sustained more falls from height $(2 \mathrm{~m}$ or more) but had similar patterns and severity of injuries. ${ }^{9}$

There have been few studies published regarding the methods to quantify the severity of the workplace related injuries so that these injuries can be analysed objectively. These include the anatomical scoring system (Abbreviated Injury Scale (AIS)) and the physiological scoring system (Glasgow Coma Scale (GCS)). ${ }^{10}$ Wyatt et al studied the effectiveness of using the AIS and its derivative, the Injury Severity Score (ISS) in objectively quantifying the severity of trauma. The conclusion is that these above-mentioned measurements may be useful to calculate the probability of survival of a patient after the traumatic event. ${ }^{11}$ The Revised Trauma Score (RTS) is calculated from a number of parameters, namely the GCS, systolic blood pressure and the respiratory rate. It has a score range of $0-12$ with lower score indicating higher severity of injury. The RTS and the ISS may be combined to give us the probability of survival the patients have.

\section{STUDY METHOD}

This study is a retrospective review of the trauma registry in a 1500-bedded acute urban public hospital over a 3-month period, from 1 April to 30 June 2015. Patients who were tourists, foreign students and/or sustained non-work-related injuries were excluded. Patients who were foreign workers, sustained work-related injuries and presented to the ED were included in our study. A foreign worker was defined as a non-Singapore citizen, non-permanent resident working in Singapore, as per the 2004 study. ${ }^{9}$ Of these, re-attendances for the same issue were excluded.

The outcomes measured include demographic data, Patient Acuity Category (PAC) (a triage category used across all Singapore public hospitals: (1) resuscitation and critically ill, (2) non-ambulatory acute ill, (3) ambulatory minor emergencies, (4) non emergencies) injury data including type of injury, location of injury, and ISS, and disposition data including discharges, admissions, follow-up and medical leave. ISS were obtained by manual coding of extracted data. The results were then analysed using descriptive statistics including frequency, percentage, mean and SD. Data were compared between admitted versus discharged patients, and 2015 versus 2004 , using the $\chi^{2}$ test. A $\mathrm{p}$ value of less than 0.05 was considered significant.

\section{Patient and public involvement}

Patients or the public were not involved in the design, or conduct, or reporting, or dissemination plans of our research.

\section{RESULTS}

Our total sample of foreign workers who sustained workrelated injuries was 1095 . This figure represents $8.8 \%$ of the total number (12 351) of workplace injuries reported in Singapore in $2015 .^{5}$ Table 1 displays the demographic characteristics and general disposition and where data are available, in comparison with the characteristics of those presenting in 2004.

The mean age was 32.8 years (SD 7.8) versus 29.6 years (SD 6.2) in $2004(\mathrm{p}<0.0001)$. Nine out of ten were men (vs $96.1 \%$ in 2004, $\mathrm{p}<0.0001$ ). The ethnicity distribution was $41.3 \%$ Bangladeshi, $23.7 \%$ Indian, $22.5 \%$ Chinese, $1.1 \%$ Malay and $11.4 \%$ others.

Only $4.7 \%$ arrived by ambulance (vs $5.2 \%$ in 2004, $\mathrm{p}=0.53)$. Vast majority arrived by other routes such as walk in $(94.7 \%)$ and police vehicle $(0.6 \%)$ versus $94.8 \%$ in 2004, $\mathrm{p}=0.61$. Most of the cases $(83.6 \%)$ were triaged to PAC 3, with $13.9 \%$ to PAC 2, $2.1 \%$ to PAC 1 and $0.5 \%$ to PAC 4. 
Table 1 Demographic characteristics and disposition of foreign workers

\begin{tabular}{|c|c|c|c|}
\hline Characteristic & $\begin{array}{l}2015 \\
n=1095\end{array}$ & $\begin{array}{l}2004 \\
n=1936\end{array}$ & $P$ value \\
\hline Mean age (SD) & $32.8(7.8)$ & $29.6(6.2)$ & $<0.0001$ \\
\hline \multicolumn{4}{|l|}{ Ethnicity (\%) } \\
\hline Chinese & $246(22.5 \%)$ & $404(20.9 \%)$ & 0.30 \\
\hline Indian & $260(23.7 \%)$ & $655(33.8 \%)$ & $<0.0001$ \\
\hline Bangladeshi & $452(41.3 \%)$ & $852(44 \%)$ & 0.0001 \\
\hline Others & $125(11.4 \%)$ & & \\
\hline \multicolumn{4}{|l|}{ Arrival (\%) } \\
\hline Ambulance & $52(4.7 \%)$ & $100(5.2 \%)$ & 0.53 \\
\hline Blunt & $856(78.2 \%)$ & $1531(79.1 \%)$ & 0.56 \\
\hline Penetrating & $210(19.2 \%)$ & $329(17 \%)$ & 0.13 \\
\hline Chemical/thermal burns & $29(2.6 \%)$ & $76(3.9 \%)$ & 0.05 \\
\hline \multicolumn{4}{|l|}{ Ocular injuries $(n=148)$} \\
\hline Wearing eye protection & $57(38.5 \%)$ & - & - \\
\hline No eye protection & $31(20.9 \%)$ & - & - \\
\hline Undocumented & $60(40.6 \%)$ & - & - \\
\hline Intervention & & & 0.0001 \\
\hline Required surgery & $88(8 \%)$ & $256(13.2 \%)$ & \\
\hline Admitted & $55(5 \%)$ & $380(19.6 \%)$ & \\
\hline Died & $0(0 \%)$ & $1(0.1 \%)$ & \\
\hline $\begin{array}{l}\text { Others, for example, discharged against advice, } \\
\text { absconded, referred to other hospitals }\end{array}$ & $17(1.54 \%)$ & - & \\
\hline Mean duration of sick leave in days (SD) & $4.3(5.5)$ & $5.1(3.4)$ & 0.0001 \\
\hline
\end{tabular}

Injury types were categorised into blunt, penetrating and chemical/thermal burns. The proportion of blunt injuries was $78.2 \%$ (vs $79.1 \%$ in $2004, \mathrm{p}=0.56$ ), penetrating was $19.2 \%$ (vs $17 \%$ in $2004, \mathrm{p}=0.13$ ) and chemical/thermal burns was $2.6 \%$ (vs $3.9 \%$ in 2004, $\mathrm{p}=0.05$ ). Compared with $13.4 \%$ in 2004 fewer $(7.9 \%)$ underwent day or inpatient surgical procedures $(\mathrm{p}<0.0001)$. Among 148 foreign workers who sustained ocular injuries $38.5 \%$ were wearing eye protection (eg, goggles), $20.9 \%$ were not wearing eye protection and $40.6 \%$ had undocumented eye protection status.

Significantly, only $5.0 \%$ were admitted (vs $19.6 \%$ in $2004, \mathrm{p}<0.0001)$. For the rest $41.6 \%$ were discharged to specialist outpatient clinics (vs 27.6\% in 2004, p<0.0001), $31.4 \%$ required no follow-up (vs $42.5 \%$ in 2004 , p<0.0001) and $12.5 \%$ were discharged to primary care (ie, general practitioner clinic). $29.9 \%$ in 2004, $\mathrm{p}<0.0001)$. Overall mean duration of sick leave was 4.3 days (SD 5.5) versus 5.1 (SD 3.4) in 2004, $\mathrm{p}<0.0001$.

There was a narrow variation in ED attendance over the days of the week, with a minimum of 106 foreign workers on Sundays and a maximum of 182 on Thursdays (figure 1).

Table 2 shows an analysis of the injury characteristics sustained by those who were discharged compared with those who were admitted.

$77.3 \%$ of discharged patients sustained blunt injuries compared with $94.5 \%$ of admitted patients $(\mathrm{p}<0.0001)$. Further, $19.9 \%$ of discharged patients sustained penetrating injuries compared with $5.5 \%$ of admitted patients 


\section{Day of ED attendance}

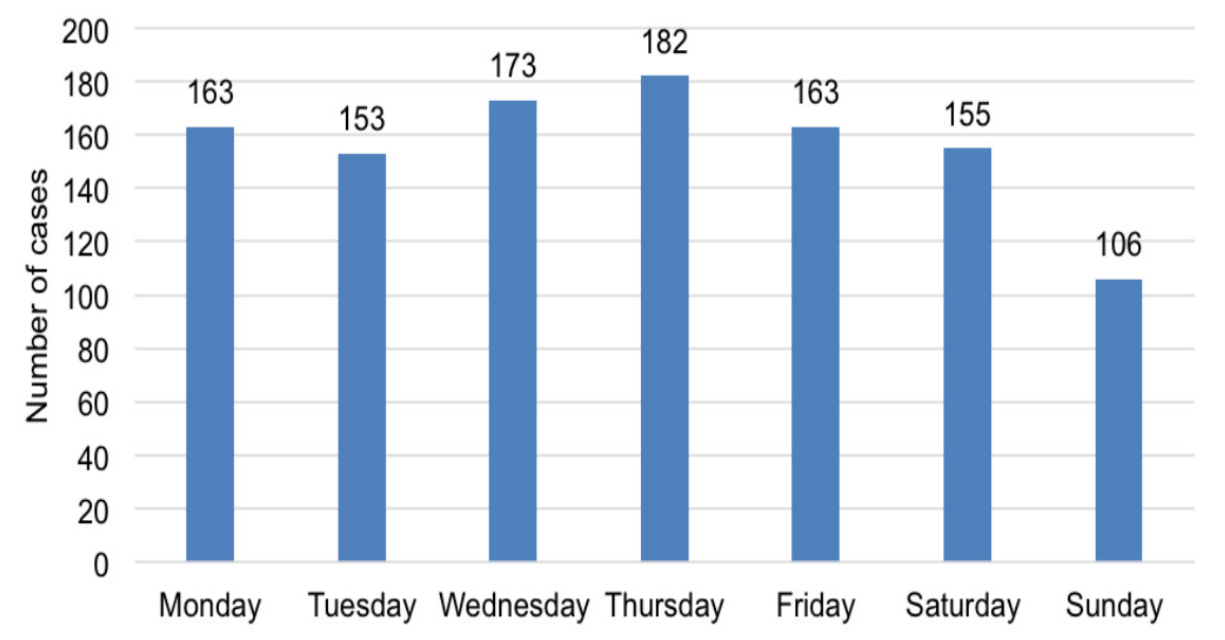

Figure 1 Day of emergency department (ED) attendance of foreign workers.

$(\mathrm{p}=0.01)$. The extremities and pelvic girdle were the regions most commonly injured. The least common site of injury was abdominal and pelvic contents, with only one case $(0.1 \%)$ among the discharged patients, and none among the admitted. Compared with admitted patients in the 2004 study, there was a significant increase

\begin{tabular}{|c|c|c|c|}
\hline & $\begin{array}{l}2015 \\
\text { discharged } \\
n=1023\end{array}$ & $\begin{array}{l}2015 \\
\text { admitted } \\
n=55\end{array}$ & $\begin{array}{l}2004 \text { admitted } \\
\mathrm{n}=380\end{array}$ \\
\hline \multicolumn{4}{|l|}{ Type of injury (\%) } \\
\hline Blunt & $791(77.3 \%)$ & $52(94.5 \%)$ & Not available \\
\hline Penetrating & $204(19.9 \%)$ & $3(5.5 \%)$ & Not available \\
\hline $\begin{array}{l}\text { Chemical/ } \\
\text { thermal burns }\end{array}$ & $28(2.7 \%)$ & $0(0 \%)$ & Not available \\
\hline \multicolumn{4}{|c|}{ Body part injured $(\%)^{*}$} \\
\hline Head and neck & $48(4.7 \%)$ & $20(36.4 \%)$ & $\begin{array}{l}39(10.3 \%) \\
(p<0.0001)\end{array}$ \\
\hline Face & $209(20.4 \%)$ & $8(14.5 \%)$ & $\begin{array}{l}9(2.3 \%) \\
(p<0.0001)\end{array}$ \\
\hline Thorax and back & $217(21.2 \%)$ & $12(21.8 \%)$ & $\begin{array}{l}13(3.4 \%) \\
(p<0.0001)\end{array}$ \\
\hline $\begin{array}{l}\text { Abdominal and } \\
\text { pelvic contents }\end{array}$ & $1(0.1 \%)$ & $0(0 \%)$ & $\begin{array}{l}22(5.8 \%) \\
(p=0.067)\end{array}$ \\
\hline $\begin{array}{l}\text { Extremities and } \\
\text { pelvic girdle }\end{array}$ & $500(48.9 \%)$ & $27(49.1 \%)$ & $\begin{array}{l}268(70.5 \%) \\
(p=0.001)\end{array}$ \\
\hline $\begin{array}{l}\text { External } \\
\text { structures }\end{array}$ & $500(48.9 \%)$ & $5(9.1 \%)$ & $\begin{array}{l}63(16.6 \%) \\
(p=0.153)\end{array}$ \\
\hline Mean ISS (SD) & $1.69(1.4)$ & $3.64(3.1)$ & $\begin{array}{l}4.3(5.5) \\
(p=0.385)\end{array}$ \\
\hline Mean RTS (SD) & $7.84(0.04)$ & $7.74(0.39)$ & $\begin{array}{l}7.8(0.2) \\
(p=0.074)\end{array}$ \\
\hline
\end{tabular}

*Percentages for body part injured may not add up to 100 as some patients had more than one body part injured.

ISS, Injury Severity Score; RTS, Revised Trauma Score. in injuries to head and neck, face, thorax and back, and a significant decrease in injuries to the extremities and pelvic girdle. The mean ISS for discharged patients was 1.69 (SD 1.4) with no historical comparison available, and for admitted patients was 3.64 (SD 3.1) (vs 4.3 (SD 5.5) in 2004, $\mathrm{p}=0.39$ ). The mean RTS for discharged patients was 7.84 (SD 0.04) with no historical comparison available, and for admitted patients was 7.74 (SD 0.39) (vs 7.8 (SD 0.2 ) in 2004, $\mathrm{p}=0.07$ ). Mean length of hospital stay for admitted patients was 2.78 days (SD 3.5), with two cases having more than 10 days of stay. There were no deaths in 2015 versus two deaths in $2004(p=0.84)$.

\section{DISCUSSION}

The differences over the past decade are expected because there have been many changes in terms of protective legislation, employment practices and health-seeking behaviour among foreign workers. Over the years, a comprehensive and holistic approach was adopted endto-end, starting from preventive efforts and education, to better care for affected workers.

The current study reveals that minor injuries are much more prevalent than the fatal and non-fatal major injuries. This could be due to better workplace safety standards and practice and stepped-up enforcement. For example, data from the Singapore Ministry of Manpower showed an increase in the number of workplaces placed under surveillance for occupational health hazards from 1698 in 2006 to 2138 in $2015 .^{8}$ Initiatives such as the Business Under Surveillance programme that provides proactive surveillance of high-risk workplace was started in 2007 and has since recruited more than 300 companies. ${ }^{5}$ It is likely that efforts in the past decade focusing on reducing severe workplace injuries has produced some sustained improvements resulting in a tilt towards more minor injuries. Furthermore, improved job skills and safety training, and provision 
of safety equipment may have reduced mishaps at the workplace. ${ }^{12}$ Finally, increased outreach by relevant government ministries and the work of activists and non-governmental organisations over the years have also likely improved foreign workers' awareness of their rights and protection under the law. This may encourage them to present for less serious conditions before they become more complicated.

In the 2004 study, the authors reported that the attendance rates of foreign workers were highest at the end of the week (Friday and Saturday), and postulated that it could be attributed to fatigue and accumulation of injury. ${ }^{9}$ Our team questioned if the observation could also reflect certain barriers faced by foreign workers in accessing healthcare, especially during working hours. In 2007, the Singapore government made a policy revision to withdraw subsidies for healthcare at public facilities for foreign workers resulting in significantly higher costs for foreign workers compared with citizens. This is likely to have had an effect of discouraging workers from seeking medical attention for minor ailments. Fortunately, this was followed by the introduction of the WICA in 2008, which laid out responsibilities of employers to provide minimum medical expenses for healthcare costs sustained during work. Some studies have raised concerns that despite the improvements in legislation related to healthcare financing of foreign workers, there likely remains a policy-practice gap that contributes to decreased accessibility in some cases. ${ }^{13} 14$ Our team reviewed the ED attendance pattern of foreign workers again in 2015 and discovered no significant differences throughout the week. Possible explanations include that employers are taking more responsibility for the wellbeing of foreign workers and encouraging them to seek medical attention at the point of injury. Alternatively, there could be an increase in health-seeking behaviour among foreign workers, and healthcare may have become more accessible now. A study done in 2014 on health-seeking behaviours of male foreign workers showed that in hypothetical injury or illness scenarios, majority responded that they would seek medical attention. ${ }^{15}$ However, up to $15 \%$ of respondents would continue to work even in presence of a work-related injury. Postulated reasons included poor awareness of entitlement for employer funded health insurance and lower income. ${ }^{16}$ Therefore, though overall healthseeking behaviours may have increased, there is still a significant proportion of foreign workers who face barriers in accessing healthcare.

Only 5\% of the foreign workers required admission, which may reflect a reduction in major injuries or a change in hospital admission criteria, practice and policy. For example, the Emergency Department Direct Access to Surgery, introduced since 2008, facilitated the completion of uncomplicated surgery for the injured worker followed by discharge within 24 hours. This resulted in an overall reduction in cost of healthcare for the provider and the patient.

The data indicate that ocular injuries $(13.5 \%)$ are quite prevalent with more than half wearing eye protection $(64.8 \%)$ at the point of injury. A 1997 study showed that only $21.7 \%$ of patients who presented with work-related ocular injury wore eye protection, ${ }^{17}$ and a study in 2008 showed a similar $21.3 \%$ who were wearing their protective eyewear when they sustained ocular injuries. ${ }^{18}$ In our study, the increased proportion of workers who were wearing their eye protection devices may reflect better provision of, and compliance to, safety devices-which may be a result of better safety training programmes. However, it is also important to reflect on why these workers sustained ocular injuries despite wearing eye protection. Possible reasons include that the eye protection was inadequate, or the workers were wearing the eye protection incorrectlyfor instance, due to lack of appropriate instruction on the proper way to don such equipment. These are two potential avenues for policy makers and employers to target in attempting to reduce ocular injuries in foreign workers. Of note, for $40.6 \%$ of patients with ocular injuries, the eye protection status was undocumented. The lack of documentation suggests a significant number of healthcare staff did not seek such information during history taking or failed to document despite asking. This indicates that there is also room for improvement for front-line healthcare staff to understand their role in injury prevention.

In 2015 there are more referrals to Specialist Outpatient Clinics (SOC) compared to 2004, where most were discharged without follow-up. This is also associated with significantly lower primary care utility in 2015 compared with in 2004. Possible explanations include the following: (1) instead of admission some injuries are deemed appropriate for urgent referral to the SOC, (2) changes in patient expectations whereby a referral to the SOC is now the expected as a standard of care and (3) changes in the doctors' referral practice whereby a SOC referral is an expected standard of care.

The results also show that the scoring systems used in major trauma (ISS and RTS) do not add value in the understanding of the minor injury disease pattern and severity sustained by foreign workers. Yet looking at the injuries, the hospitalisation and sick leave and therefore the projected loss of productivity, the impact of these minor injuries should not be underestimated. Perhaps a minor trauma scoring system needs to be developed to provide new insight.

One limitation of this study was that it was conducted in a single centre and may not reflect the pattern of injuries sustained by foreign workers across the nation. The types of industries present in the catchment area served by a particular hospital may differ compared with another due to the timing and scale of developmental projects as well as geographical location. Certain industries such as construction are known to be at higher risk of major workplace injuries. ${ }^{8}$ It is possible that a hospital close to ongoing construction of a high-rise building may result in more injuries due to fall from height. Our team did not gather data about the industries in our vicinity, who employed foreign workers, at the time of the study. Furthermore, while the 2015 data show no fatalities compared with two fatalities in the 2004 study — which may reflect the overall decrease in 
workplace fatality rate-as this is a single centre study, it may not be representative of the fatality rate of workplace injuries sustained by foreign workers in the country. However, this centre also receives the highest proportion of trauma patients in the country, which may contribute to the sample being more representative. The retrospective nature of this study also lends itself to the inherent limitations of such a design, including issues of recall bias for delayed presentations of illnesses and incompleteness of information gathered by the attending physician. As our study did not collect data regarding the exact nature of jobs performed by the foreign workers, our results may not be generalisable to all foreign workers. While the majority of foreign workers still undertake jobs that are labour intensive, there is an increased proportion performing highly skilled/managerial tasks over the years. It is likely that the patterns of injuries differ significantly between these groups. Further, there was limited amount of analysis to be done in terms of comparison between the discharged and admitted foreign workers in 2015, due to the difference in sample size between the two groups. In addition, we did not collect data on the disposition and follow-up of admitted patients, which may be area for further study to compare the utilisation of healthcare resources in follow-up of discharged patients versus admitted patients.

Since the conclusion of this study, the WICA has since been amended and came into effect from 1 January 2020. Among the key changes include expanding scope of compensation to light duties, compulsory reporting for any instance of medical leave or light duties issued for work accident and expanded mandatory insurance coverage to nonmanual employees. These combined are likely to further alter workers' health seeking habits and physician medical leave prescription practices.

\section{CONCLUSION}

Compared with a decade ago, there are fewer major and fatal work-related injuries, which may be attributed to better workplace safety in Singapore. The rise in minor injuries is surprisingly associated with a higher utilisation of tertiary-level SOC services, which should be examined for their necessity given that most of these injuries are minor. Further, the use of the scoring systems RTS and ISS have not proven to be useful in this setting. Suggested areas for future research include developing a minor trauma scoring system that could aid in policy-making decisions with regards to loss of productivity and workplace safety. Further, there may be value in encouraging front line healthcare professionals to document use of safety devices at workplace, for example, use of ocular protection in patients who present with ocular injuries, as this data may prove useful in aiding injury prevention.

Contributors All authors contributed to the design of the study and its protocol. YJDQ, SV, AN participated in collation of data, its interpretation and statistical analysis. KYT supervised the study overall. All authors contributed to development of the manuscript and all authors have approved the final version.

Funding The authors have not declared a specific grant for this research from any funding agency in the public, commercial or not-for-profit sectors.

Competing interests None declared.

Patient and public involvement Patients and/or the public were not involved in the design, or conduct, or reporting, or dissemination plans of this research.

Patient consent for publication Not required.

Ethics approval All necessary ethics committee approval was secured for the study from the Domain Specific Review Board, Office of Human Research Protection Programme, National Healthcare Group. Reference number 2016/01301.

Provenance and peer review Not commissioned; externally peer reviewed.

Data availability statement Data are available upon reasonable request.

Open access This is an open access article distributed in accordance with the Creative Commons Attribution Non Commercial (CC BY-NC 4.0) license, which permits others to distribute, remix, adapt, build upon this work non-commercially, and license their derivative works on different terms, provided the original work is properly cited, appropriate credit is given, any changes made indicated, and the use is non-commercial. See: http://creativecommons.org/licenses/by-nc/4.0/.

ORCID iD

Yong Jing Daniel Quek http://orcid.org/0000-0003-2892-0805

\section{REFERENCES}

1 MOM. Foreign workforce numbers [Internet]. Available: http:// www.mom.gov.sg/documents-and-publications/foreign-workforcenumbers [Accessed 5 Apr 2020].

$2 \mathrm{MOH}$. Singapore health facts [Internet]. Available: https://www.moh. gov.sg/content/moh_web/home/statistics/Health_Facts_Singapore. html [Accessed 5 Apr 2017].

3 Chen K, Tham KY, Seow E, et al. Extent and appropriateness of emergency department services usage by foreign workers in Singapore. Ann Acad Med Singap 1999;28:199-204.

4 Yoke Y, Tan W, Manickam K. Economic cost of work-related injuries and ill-health in Singapore. Workplace Safety and Health Institute Publications, 2013.

5 Workplace Safety and Health Institute. Workplace safety and health report. Singapore, 2016.

6 Ministry of Manpower. Workplace safety and health 2018 plus. Singapore, 2016.

7 The Occupational Safety and Health Division (OSHD) of the Ministry Of Manpower. 50 years, one vision - transforming Singapore into a nation of Wsh excellence, 2016.

8 Workplace Safety and Health Institute. Workplace safety and health report. Singapore, 2019.

9 Carangan M, Tham KY, Seow E. Work-related injury sustained by foreign workers in Singapore. Ann Acad Med Singap 2004;33:209-13.

10 McGowan A. Scoring systems. Curr Orthop 1993;7:4-8.

11 Rajaraman N, Yip T, Kuan BYH. Exclusion of migrant workers from national UHC Systems-Perspectives from HealthServe, a Non-profit organisation in Singapore. Asian Bioeth Rev 2020;12:1-12.

12 Ong VYK, Habibah AK, Lee FCY. Safety among foreign workers and impact on emergency medicine services in Singapore. Singapore Med J 2006;47:121.

13 Ang JW, Koh CJ, Chua BW, et al. Are migrant workers in Singapore receiving adequate healthcare? A survey of doctors working in public tertiary healthcare institutions. Singapore Med J 2020;61:540-7.

14 Wyatt JP, Beard D, Busuttil A. Quantifying injury and predicting outcome after trauma. Forensic Sci Int 1998;95:57-66.

15 Lee W, Neo A, Tan S, et al. Health-seeking behaviour of male foreign migrant workers living in a dormitory in Singapore. BMC Health Serv Res 2014;14.

16 Ministry of Manpower. Employment of foreign manpower act (Chapter 91A). Singapore, 2011: p. $4 .$.

17 Voon LW, See J, Wong TY. The epidemiology of ocular trauma in Singapore: perspective from the emergency service of a large tertiary hospital. Eye 2001;15:75-81.

18 Ngo CS, Leo SW. Industrial accident-related ocular emergencies in a tertiary hospital in Singapore. Singapore Med J 2008;49:280-5. 